Proc. Estonian Acad. Sci. Eng., 2005, 11, 1, 46-58

\title{
On micromechanical problems of erosive wear of particle reinforced composites
}

\author{
Irina Hussainova \\ Department of Materials Technology, Tallinn University of Technology, Ehitajate tee 5, 19086 \\ Tallinn, Estonia; irhus@staff.ttu.ee \\ Received 11 February 2004, in revised form 23 August 2004

\begin{abstract}
Particle reinforced composites is a success story from the viewpoint of their numerous applications. The main objective of this paper is to review the contributions of solid mechanics research to the development of composite materials and structures and to better understanding of the multiphase material behaviour in a tribological environment. The effect of microstructural features on the wear of multiphase materials is analysed for hard carbide particle reinforced composites.
\end{abstract}

Key words: particle reinforced composites, residual stress, micromechanics, wear.

\section{INTRODUCTION}

Composite materials offer exciting advantages over more traditional metallic materials. Modern advanced composites are a success story from the viewpoint of their numerous applications, ranging from tennis rackets to advanced space vehicles. Composite materials consist of fibres, whiskers or particles known as the reinforcement phase in a common matrix. The purpose of the matrix is to provide lateral support to the reinforcements. Structural composites are characterized by high performance, light weight and tailored properties. From their early introduction in high-performance aircrafts and spacecrafts, boats and sports equipment to their recent adoption in ship and marine constructions and bridge, road and rail vehicles, composite and sandwich structures have not only replaced more traditional materials but opened the door for the production of entirely new devices and structures. However, more wide application of composites depends on the cost of production, quality of manufacturing, structural response and long-term durability. The lack of design criteria and predictive models for 
durable applications of cermets poses a significant barrier to wider application of ceramic-metal composites.

The general aim of material investigations is complete understanding of the material behaviour in an aggressive environment and formulation of the principles of materials selection for their use in different service conditions. Micromechanics can bridge the gap between macroscopic properties of heterogeneous materials and their microstructural parameters.

Application of solid mechanics to contacting surfaces began with the publication of H. Hertz's classical paper "On the contact of elastic solids" in 1882. Removal of the restriction "perfectly elastic bodies" has led to more realistic consideration of the multibody contact. The present paper focuses on problems that arise during fabrication and application of an undamaged material beyond the purely elastic response. The effect of microstructural features on the wear of multiphase materials is analysed in hard carbide particle reinforced composites. Contribution of solid mechanics research to the development of composite materials and structures is reviewed.

\section{MICROSTRUCTURE OF THE MATERIALS}

Basically there are two ways to obtain a high volume fraction of carbides in an alloy: with melt solidification (M/S) or powder metallurgy $(\mathrm{P} / \mathrm{M})$ processing techniques. These methods are based on the fact that carbide particles are extremely hard; hence, the resulting composites are expected to possess high hardness and wear resistance. A ductile second phase is used to improve the toughness of materials. In this way, a composite structure combines the wearand corrosion-resistance properties of the carbides with the enhanced toughness of the metallic phase. However, the ductile phase toughening typically results in a drop in the hardness of the composite $\left[{ }^{1,2}\right]$.

The morphology and distribution of hard particles in composite materials may be different for different grades. For example, the microstructure of the plain WC-Co-cemented carbide consists of WC grains of irregular shape embedded in the cobalt-rich binder phase (Fig. 1). The cobalt binder contracts during cooling, leaving the WC grains under compression $\left[{ }^{3}\right]$ and it undergoes a transformation from metastable to stable phase during deformation and consequently has a high stacking fault level. Reprecipitation onto TiC grains results in the typical cermet microstructure: core-rim structured hard grains surrounded by a tough metallic binder phase forming TiC-Mo $\mathrm{M}_{2} \mathrm{C}-\mathrm{Ni}$ cermet structure (Fig. 1b). Unlike the angular shape of the tungsten carbide (Fig. 1a), the shape of TiC, when sintered in Ni(Mo), is rounded. Replacing $10 \mathrm{wt} \%$ of Ni binder with Mo resulted in complete wetting (i.e. contact angle goes to $0^{\circ}$ ). The majority of Mo is found within the carbide phase, forming $(\mathrm{Ti}, \mathrm{Mo}) \mathrm{C}$ complex carbide $\left[{ }^{4}\right]$. The hard phases, which are present in the material, consist of a core, rich in titanium carbide and a molybdenum carbide rich shell; core-rim structured hard grains are surrounded by a tough metallic binder phase forming $\mathrm{TiC}-\mathrm{Mo}_{2} \mathrm{C}-\mathrm{Ni}$ material (Fig. 1a). The outer and inner 


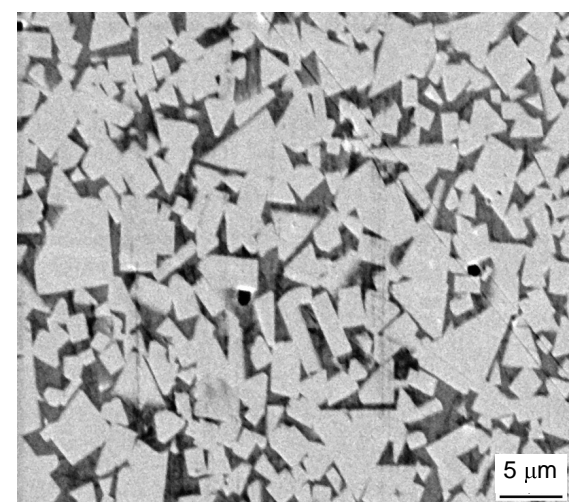

(a)

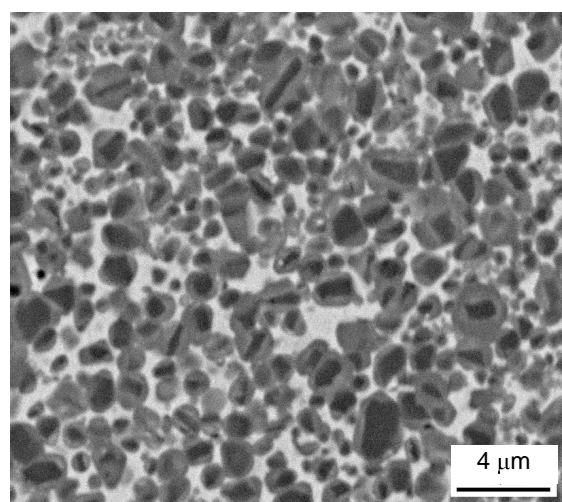

(b)

Fig. 1. SEM micrographs of ceramic-metal composites: (a) WC-Co; (b) TiC-NiMo.

layers of the rim contain also some amount of Mo and only the very center of the core shows no additions. Such a structure results in a decrease of the carbide phase continuity and an increase in the interphase bond strength. Because of the core-rim structure, there are no significant differences in mechanical properties of the material at boundary interfaces. A small amount of microstructural flaws such as voids, interphase debonding and binder microcracks are observed on TiC-NiMo surface.

The microstructural parameters, which affect mechanical properties, are binder volume, binder mean free path, carbide grain size and size distribution, porosity and carbide phase contiguity. These parameters are interrelated and their individual effect on mechanical properties is difficult to determine. Additional microstructural features, which have strongly detrimental effects on strength, are the occasional presence of brittle and hard third phase due to a slight deficiency in carbon and the presence of graphite due to the excess of carbon or pores, defects, inclusions and large grains, which act as fracture initiation sites $\left[^{5}\right]$.

\section{EROSIVE WEAR}

In an attempt to rank materials based on their intrinsic properties, several models have been developed, which assume that subsurface lateral fracture is responsible for most of the material being removed by erosive wear $\left[{ }^{6,7}\right]$. For fixed particle and test parameters, the erosion rate $E$ of the target materials can generally be expressed as follows:

$$
E=C K_{I C}^{m} H^{n}=C \zeta,
$$

where the exponents $m$ and $n$ have negative values, $C$ is a constant of proportionality, $K_{I C}$ is material fracture toughness and $H$ is hardness. Evans 
et al. $\left[^{6}\right]$ proposed $m=-1.3$ and $n=-0.25$. Assuming that all environmental factors are constant, the volume wear of various grades should be controlled by the overall magnitude of $\zeta$, with low values of $\zeta$ predicting lower wear rates.

The data for the ceramic-metal composites (WC-Co; TiC-NiMo; TiC-steel; $\mathrm{Cr}_{3} \mathrm{C}_{2}-\mathrm{Ni}$ ), examined in $\left.{ }^{8}\right]$, make it clear that this approach does not provide a consistent correlation between the erosion rate and $\zeta$, as it is apparent from Fig. 2 (erodent: $\mathrm{SiC}$ particles). One possible reason for this may be that the lateral fracture is not the predominant fracture mechanism in these materials and material removal in erosive environment results from a combination of three processes: plastic deformation, transgranular subsurface fracture and intergranular fracture or displacement of carbide grains. The extent of one or another mechanism depends on microstructural characteristics of the material, which influence plastic deformation and brittle fracture. For example, the high performance of the WC-Co cermet may be attributed to a high toughness of carbide grains that is high enough to withstand contacts with high amounts of dissipated energy without microfracture $\left[{ }^{5}\right]$. In contrast to the tough WC particles, $\mathrm{TiC}$ and $\mathrm{Cr}_{3} \mathrm{C}_{2}$ grains are very brittle (fracture toughness of about $3 \mathrm{MPa} \mathrm{m}^{1 / 2}$ ) in nature $\left.{ }^{2,9}\right]$.

Although fracture toughness of the TiC-based cermets differs a little from that of WC-based alloys, the TiC skeleton seems to be much more brittle than the tungsten carbide based ones $\left[{ }^{5}\right]$. It is apparent that the fracture toughness of the hard skeleton is a more important parameter for tribological application than the measured bulk fracture toughness of sintering materials.

Another reason may be that, although widely accepted, the indentation fracture toughness technique used is not the best method for determining the toughness of heterogeneous materials intended for tribological environments. Recently, several studies $\left.{ }^{2,5,8,10}\right]$ have indicated that for many ceramic-based composites the local toughness based on "short-crack" testing is an important

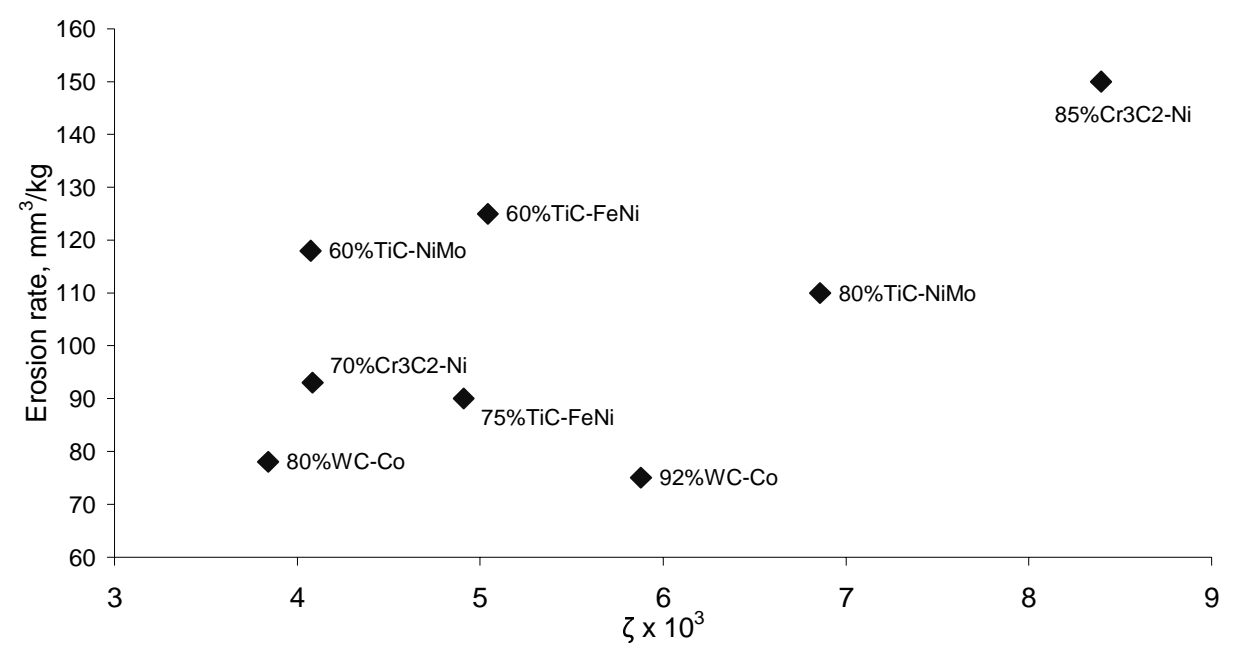

Fig. 2. Erosion rate as a function of $\zeta$ for different composites. 
parameter to be used instead of bulk toughness based on "long-crack" testing. Moreover, it must be noted that the values of the hardness are based on low strain rate hardness measurements and may be somewhat different from the values of the hardness actually relevant in impact conditions occurring in erosion.

Obviously, behaviour of the composites cannot be evaluated by looking only at one of the measured mechanical characteristics or by looking at a blend of the bulk properties. First of all the internal stress state should be taken into account. The internal state of materials depends on the microstructural parameters.

\section{STRESSES IN MATERIALS}

Composite materials possess stresses due to strains that are not caused by imposed mechanical loads, for example, thermal strains, moisture absorption strains or phase transformation strains. These strains can be variable and dissimilar in constituent phases and are not compatible between them. If the composite is disassembled and the grains are subjected to a uniform thermal treatment, it would develop thermal strains that would prevent reassembling the composite without application of additional traction $\left[{ }^{11}\right]$. Of course, compatibility of the total strains is required for the material and structural integrity; that is obtained with residual elastic strains that create the residual stresses. Their magnitudes vary, but may be quite substantial and exceed those induced by mechanical loading. This is of particular concern in composite systems processed at and cooled from high temperatures. Alone or in superposition with the mechanical stresses, the residual stress fields may cause internal damage and lead to changes in elasticity modules, strength and other physical properties $\left[{ }^{12}\right]$.

The required energy release $G$ for damage propagation can be calculated from a global energy balance. For multi-axial loading, $G$ can be expressed in terms of the effective compliance tensor $S\left[{ }^{13}\right]$ :

$$
G=\left(\frac{V}{2}\right) \sigma^{2} \frac{\mathrm{d} S}{\mathrm{~d} A},
$$

where $\sigma$ is the externally applied stress tensor, $V$ is the specimen volume and $A$ is an increment in the total crack area.

Both the interphase debonding and microcracks within the Ni binder in the TiC$\mathrm{Ni}$ grade with low content of molybdenum or within steel binder in the TiC-steel cermet (Fig. 3) prove the presence of large residual tensile stresses. It is common for cracks in composites to be diverted along some structural features $\left[{ }^{14}\right]$.

Unfortunately, the basic result, Eq. (2), is almost never correct for the analysis of composite fracture since residual stresses are ignored. However, because of the mismatch in thermal expansion coefficients between phases, multiphase materials inevitably develop residual stresses as they cool down from the processing temperature to the room temperature. Finally, composites always have interfaces between their phases. These interfaces, being imperfect, influence the energy release rate. 


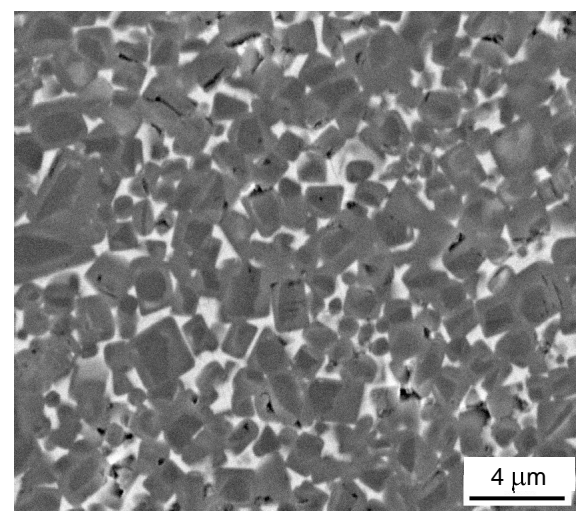

(a)

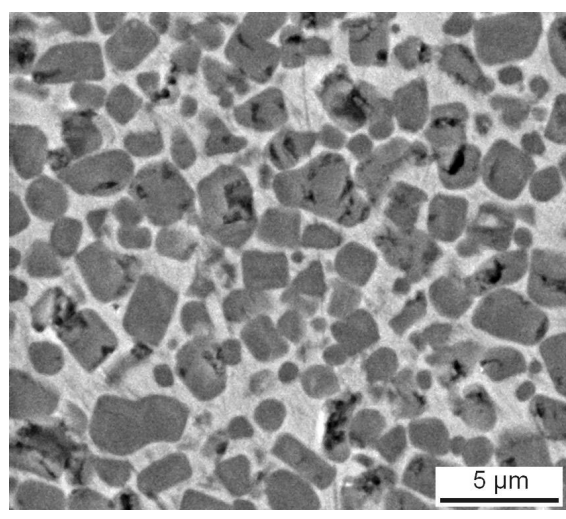

(b)

Fig. 3. SEM micrographs of ceramic-metal composites: (a) TiC-Ni; (b) TiC-steel.

The microstructural features of multiphase materials with typical sizes of reinforcements up to $100 \mu \mathrm{m}$ restrict deformation of the phases to very small and constrained volumes. If phases are well bonded, all the inelastic deformation is concentrated in the tough phase. In weakly bonded or partially debonded systems, displacement discontinuities, caused by interface separation and sliding, may contribute to a certain apparently inelastic microscopic deformation mode $\left[{ }^{11,15}\right]$.

\section{THERMOMECHANICAL EFFECTS}

\subsection{Effect of thermal residual stresses on the composite behaviour}

Due to mismatch of the coefficients of thermal expansion $\alpha$ of the matrix and inclusions, a change in temperature produces internal stress in the composite. Since $\alpha$ of the metallic matrix is greater than that of the ceramic particles, the matrix shrinks tight around the particles, resulting in the internal tensile stresses in the matrix and compressive stresses in the particles. The local plastic deformation may occur if the residual stresses exceed the yield strength of the matrix during the cooling process. Some models have been developed to tackle the thermal residual stresses and their effect on the effective mechanical performance of multiphase materials, either analytically $\left[{ }^{16,17,18}\right]$ or numerically $\left[{ }^{11,19}\right]$. In $\left[{ }^{20}\right]$ the method of parametric study of the effect of the residual stresses on the effective elasto-plastic behaviour of composites is proposed.

The local stress $\Sigma$ in the composite consists of the far-field stress $\sigma_{\mathrm{I}}$, due to the applied load, and of the stress $\sigma_{\mathrm{II}}$ caused by eigenstrain $\varepsilon: \Sigma=\sigma_{\mathrm{I}}+\sigma_{\mathrm{II}}$.

The plastic flow of the composite is controlled by local stresses in the matrix. The overall elasto-plastic behaviour of a multiphase material depends on the response of the matrix to the homogenization-averaging procedure. That procedure is described in detail elsewhere $\left[{ }^{16,18,20}\right]$. 
If there are no external stresses $\left(\sigma_{\mathrm{I}}=0\right)$, the onset of yielding of the composites owing to thermal stress can be determined under the condition of $\sigma_{\text {eff }}=\sigma_{\text {II }}\left(\sigma_{\text {eff }}\right.$ is the effective stress of the matrix $)$. The matrix stress - plastic strain law can be expressed as $\left[{ }^{18}\right]$ :

$$
\sigma_{\text {eff }}=\sigma_{\mathrm{y}}+h\left(\varepsilon^{\mathrm{p}}\right)^{n} .
$$

Here $\sigma_{\mathrm{y}}, h$ and $n$ are the yield stress and the strain-hardening parameters of the matrix, respectively, and $\varepsilon^{\mathrm{p}}$ is the effective plastic strain.

To account for the change of matrix constraints to particles due to plastic flow, the secant module method $\left[{ }^{18,20}\right]$ is applied so that the modulus of elasticity $E_{0}^{\mathrm{s}}$ and Poisson ratio $v_{0}^{\mathrm{s}}$ of the matrix are modified and become dependent on the equivalent plastic strain as:

$$
\begin{gathered}
E_{0}^{\mathrm{s}}=\frac{1}{\left(\frac{1}{E_{0}}+\frac{\sigma_{\mathrm{y}}+h\left(\varepsilon^{\mathrm{p}}\right)^{n}}{\varepsilon^{\mathrm{p}}}\right)}, \\
v_{0}^{\mathrm{s}}=\frac{1}{2}-\left(\frac{1}{2}-v_{0}\right) \frac{E_{0}^{\mathrm{s}}}{E_{0}} .
\end{gathered}
$$

The superscript "s" refers to the application of the secant module method; $E_{0}$ and $v_{0}$ are elastic parameters of the binder.

The effect of the temperature change can be simulated by the eigenstrain

$$
\varepsilon=\left(\alpha_{1}-\alpha_{0}\right) \Delta T,
$$

where $\alpha_{1}$ and $\alpha_{0}$ are coefficients of thermal expansion of the inclusion and matrix, respectively, $\Delta T$ is the temperature drop during the cooling process. It is seen that the effects induced by the temperature drop enhance the yield stress of the matrix and generation of internal stresses in the hard particles and the matrix.

With the far field mechanical loading $\sigma_{\mathrm{I}}$ the matrix hardening law is given $\left[{ }^{18}\right]$ as:

$$
\sigma_{\text {eff }}=\sigma_{\mathrm{y}}+h\left(\varepsilon^{\mathrm{p}}+\varepsilon_{0}^{\mathrm{p}}\right)^{n},
$$

where $\varepsilon_{0}^{\mathrm{p}}$ is the homogenized effective plastic strain of the matrix at the end of cooling.

Consider the SiC-Al composite with binder parameters as follows: $E_{0}=$ $73 \mathrm{GPa}, \quad v_{0}=0.33, \quad \sigma_{\mathrm{y}}=170 \mathrm{MPa}, \quad h=577 \mathrm{MPa}\left[{ }^{20}\right], \quad n=0.37, \quad \alpha_{0}=21.5 \times$ $10^{-6} /{ }^{\circ} \mathrm{C}$; and carbide particle parameters: $\alpha_{1}=3.8 \times 10^{-6} /{ }^{\circ} \mathrm{C} ; \quad E=480 \mathrm{GPa}$, $v=0.17$. It was shown $\left[{ }^{18,20}\right]$ that the equivalent plastic strain $\varepsilon_{0}^{\mathrm{p}}$ increases with the volume fraction of reinforcements. The effect of thermal residual stresses on the overall yield strength is demonstrated in Fig. 4 as the dependence of the normalized overall yield strength on the aspect ratio of the reinforcement. Aspect 


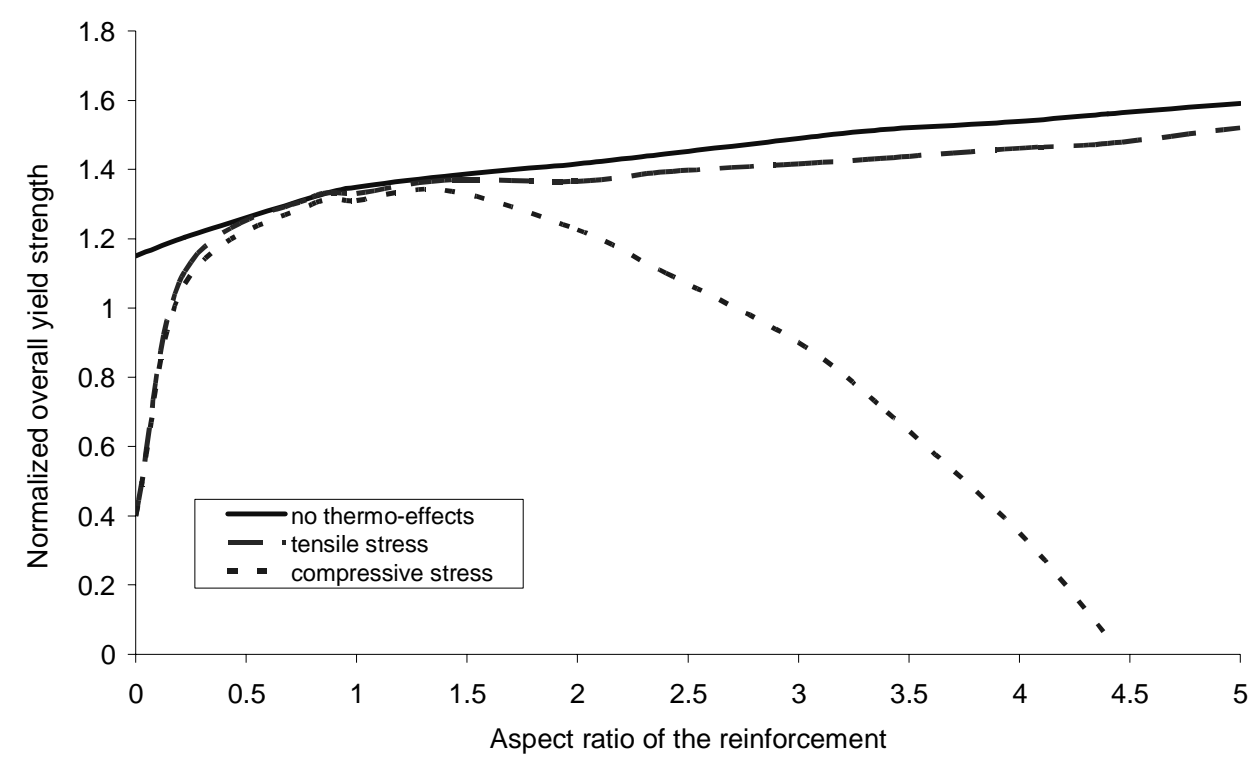

Fig. 4. The effect of aspect ratio of the reinforcement particles on the yield strength.

ratio shows the deviation of the form of the particle from the spherical one and is $>1$ for a prolate particle and $<1$ for an oblate one.

The tensile yield strength of cermets is nominally greater than the compressive strength, and both strengths are less than that without thermal residual stresses regardless of the aspect ratio and volume fracture of reinforcements. With a large aspect ratio (particles are short fibres), the compressive strength could be negligible, indicating that there is no elastic region for further compression. On the other hand, when particles are spherical, both the tensile and the compressive strength are not affected by the internal thermal stresses. The strength difference becomes more significant with the increase in the volume fraction of reinforcements $\left[{ }^{20}\right]$.

These results show that residual stresses should be taken into account when the properties of a multiphase material are to be predicted. Rounded particles have a better erosion resistance as compared with materials consisting of irregularly shaped grains if other parameters are similar. For example, TiC-NiMo grade with rounded particles and Vickers hardness of $1050 \mathrm{HV}$ has the erosion resistance twice as high as $\mathrm{TiC}-\mathrm{Fe}(\mathrm{Ni})$ grade with prismatic particles and the same hardness. Details on erosion rate determination are given in $\left[{ }^{4,21}\right]$.

\subsection{Thermomechanical effects on erosive wear}

The local deformation caused by the erosive impact of a solid particle on a target material and the possibility of adiabatic conditions associated with high strain rates in a material of low thermal conductivity may cause an increase of the 
temperature. The extent of thermal effects is determined by the competition between heat generation and heat dissipation. These two phenomena are controlled by several properties, and the response of different materials may be very different.

High flash temperature may briefly soften the material and may result in a thermal stress field superimposed upon the mechanical stress field. It may also be the reason for a local phase transformation in multiphase materials, for instance, for the formation of austenite which then quenches to martensite in carbon and low-alloy steels. Cobalt in WC-Co alloys exhibits a transformation (equilibrium temperature $417^{\circ} \mathrm{C}$ ) from its low-temperature hexagonal close-packed structure with limited slip ductility to a cubic structure that is fully ductile. From a physical point of view, the fracture under high temperature is a thermally activated process with the height of the energy barrier being reduced by the applied stress.

Despite certain chemical inertness, the surfaces of most ceramics and cermets are susceptible to tribomechanical reactions that lead to the formation of surface films and thus to the modification of their wear behaviour. These reactions occur much more rapidly at impact contact than on a free surface at the same bulk temperature. Oxidation is one of the mechanisms of wear in carbide composite materials. That may be one of the reasons of higher performance of $\mathrm{Ni}(\mathrm{Mo})$ bonded cermets as compared to the steel-bonded ones.

To avoid nucleation and propagation of the thermal cracks caused by local overheating, the materials with a low difference in the coefficient of thermal expansion of different phases and high thermal conductivity $K$ are preferable (Table 1).

Although the difference in thermal expansion for TiC-based cermets is not as large as for the WC-Co ones, the area of the flash temperature concentration is too small because of low value of thermal conductivity and a binder phase can be melted or plastically deformed and extruded (Fig. 5). Carbide grains lose their protective binder, forming a thin subsurface transition layer with strength parameters differing from these of bulk parameters. Because of the low fracture toughness of titanium carbides, the fracture occurs in a much more brittle manner in comparison with tungsten carbides. In the WC-Co system the propagation of thermally induced microcracks is restricted because of high fracture toughness, high value of thermal conductivity and possibility of dislocation movement without formation of a fault stack for the nucleation of microcracks.

Table 1. Thermal properties of some carbide-based composites

\begin{tabular}{l|c|c|c}
\hline Material & $\begin{array}{c}\text { Coefficient of thermal } \\
\text { expansion of the } \\
\text { carbide phase, } \\
\alpha_{1} \times 10^{6}, K^{-1}\end{array}$ & $\begin{array}{c}\text { Coefficient of } \\
\text { thermal expansion of } \\
\text { the binder phase, } \\
\alpha_{0} \times 10^{6}, K^{-1}\end{array}$ & $\begin{array}{c}\text { Thermal conductivity } \\
\text { of the cermet, } \\
\mathrm{Wm}^{-1} K^{-1}\end{array}$ \\
\hline WC-Co & 3.84 & 12.3 & 92 \\
TiC-steel & 7.4 & $12-16$ & 15 \\
TiC-Mo2C-Ni & 9 & 13.3 & 18
\end{tabular}




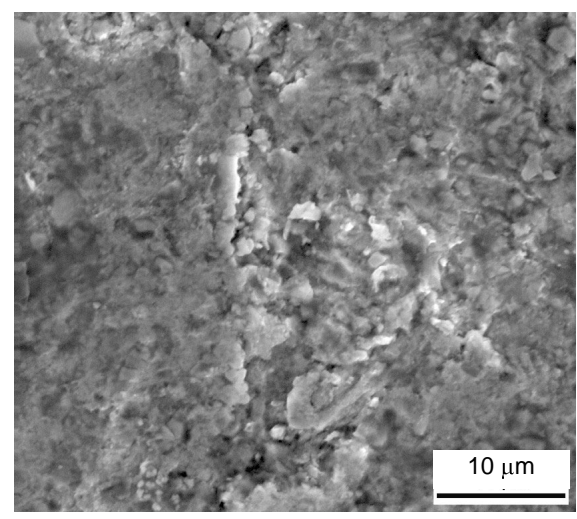

(a)

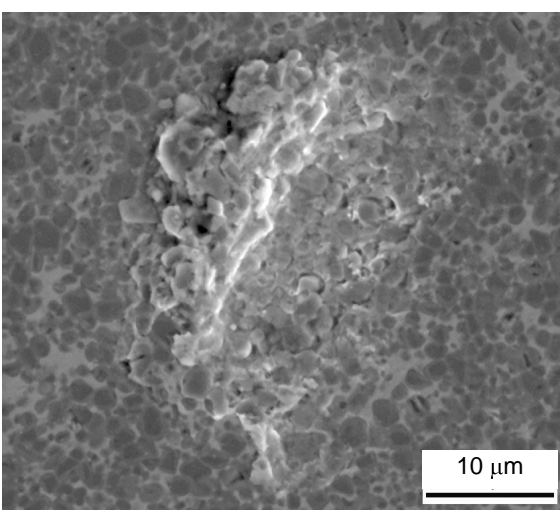

(b)

Fig. 5. SEM micrographs of a worn surface of TiC-NiMo (a) and single impact crater produced in TiC-based ceramic-metal composite by a silicon carbide particle (b).

Since the coefficients of thermal expansion of constituent phases are usually quite dissimilar, cooling from high fabrication and processing temperatures to room temperature almost always generates sufficiently high thermal stresses for the onset of local viscoplastic deformations. Additional inelastic deformation may be generated by mechanical pressure, applied during fabrication. Together with the stresses imposed by mechanical loads, composite materials obtain residual stresses due to eigenstrains or transformation strains in the constituents. The residual stresses vary, but may be sufficiently high to cause internal damage either alone or in superposition with the mechanical stresses. Therefore these characteristics should be taken into consideration in any discussion of the tribological performance of bulk materials.

\section{SOME REMARKS ON THE FRACTURE OF COMPOSITES}

By their very nature, composites consist of several constituents of different geometry and properties, joined along many interfaces. That contributes to some forms of local fracture, which are typically constrained to nucleation of cracks and to their distribution through the volume of the material. Reinforcing particles may not accommodate a major crack by themselves because their small size (a few micrometers) precludes formation of critical size Griffith cracks even in reinforcements made of low-toughness materials. This size effect is the main source of the high strength of fine-grained composites.

Calculation of the energy release rate by composite fracture that includes the effect of residual stresses, imperfect interfaces and traction loaded cracks has recently been considered in $\left[{ }^{22,23}\right]$. The general approach is to divide the total stresses into mechanical stresses and residual stresses. The general energy release $G$ can be written as 


$$
G=G_{\text {mech }}+G_{\text {res }} .
$$

The first term is the traditional energy release rate that considers only mechanical stresses and the second term accounts for residual stresses $\left[{ }^{23}\right]$.

This approach $\left[{ }^{22-24}\right]$ reveals two important points. First, more than half of the total energy, released during crack growth, is released by residual stresses. Therefore, to estimate the composite reliability, the residual stresses should be taken into consideration; ignoring them may lead to erroneous characterization of the true interface properties. However, interfaces may impede or promote damage evolution. On one hand, they can deflect matrix cracks from the reinforcements and allow crack bridging processes that impose a major constraint on the extension of the matrix cracks. On the other hand, if exposed to high peeling and shear stresses, they may open interfacial cracks between the matrix and reinforcements.

Second, inclusion of frictional loads into energy release rate is essential to the development of the fracture mechanics analysis of micro-bonding and pull-out of small carbide particles from the surface during erosion and abrasion.

The residual tensile stresses result in a local decrease of the fracture toughness of the boundaries, leading to an increase of the tendency of material removal in the wear environment. The true toughness can be only calculated by subtracting the frictional effects to get the actual amount of energy, released as the crack grows.

\section{CONCLUDING REMARKS}

It is believed that an improvement in wear resistance is mainly due to the increase in interphase bond strength and to the decrease in the number of microstructural flaws, which are stress concentrators needed for nucleation and propagation of cracks, resulting in the removal of the material. Strong interfacial bonding between constituent phases prevents eruption of hard particles during erosion.

The materials with low difference in the coefficient of thermal expansion of phases and of high thermal conductivity are preferable.

General problems of deformation, damage initiation and growth, and failure of composite materials, subjected to complex loading conditions in severe environments, require much attention in future research. The entire life cycle of the structure has to be taken into consideration, from the fabrication and processing phase through evolution of the elastic and inelastic and damage assisted deformation to final fracture.

The composition of the binder phase determines whether stresses at the boundary are tensile or compressive and thus determines whether fracture of the material is inter-granular or intra-granular. Residual stresses that promote coherence of interfaces should be generated where possible. The fabrication methods need to be modelled and controlled to minimize the density of pre- 
existing flaws and to improve the initial stress state. Recent advances in the design of physical properties of composite systems is to be exploited in future structural design.

Resistance of composite structures to dynamic and impact loads needs to be improved both by experimentally supported modelling and by selection of adequate methods for the determination of micro-structural properties of the materials.

\section{ACKNOWLEDGEMENT}

This research was supported by the Estonian Science Foundation (grant No. 5015).

\section{REFERENCES}

1. Doğan, C. and Hawk, J. Role of composition and microstructure in the abrasive wear of highalumina ceramics. Wear, 1999, 225-229, 1050-1058.

2. Dogan, O., Hawk, J., Tylczak, J. and Wilson, R. Wear of titanium carbide reinforced metal matrix composites. Wear, 1999, 225-229, 758-769.

3. Larssen-Basse, J. Effect of composition, microstructure and service conditions on the wear of cemented carbides. J. Met., 1983, November, 35-41.

4. Hussainova, I. Effect of microstructure on the erosive wear of titanium carbide based cermets. Wear, 2003, 255, 121-128.

5. Hussainova, I. Microstructure and erosive wear in ceramic-based composites. Wear, 2005, 258, 357-365.

6. Evans, A., Golden, M. and Rosenblatt, M. Impact damage in brittle materials. Proc. Roy. Soc. London, 1978, A361, 343-353.

7. Ruff, A. and Wiederhorn, S. Erosion by solid particle impact. In Treatise on Materials Science and Technology. Academic Pr., New York, 1979, vol. 16, 69-126.

8. Hussainova, I. and Viljus, M. Microstructural effects on wear of non-homogeneous hardmetal materials. Proc. Estonian Acad. Sci. Eng., 2003, 9, 126-136.

9. Viatte, T., Bolognini, S., Cutard, T., Feusier, G. and Mari, D. Investigation into the potential of a composite combining toughness and plastic deformation resistance. Int. J. Refract. Met. Hard Mater., 1999, 17, 79-89.

10. Doğan, C. and Hawk, J. Microstructure and abrasive wear in silicon nitride ceramics. Wear, 2001, 250, 256-263.

11. Dvorak, G. Composite materials: inelastic behaviour. Int. J. Solids Struct., 2000, 37, 155-170.

12. Lu, T. and Hutchinson, J. Effect of matrix cracking on the overall thermal conductivity of fiber reinforced composites. Philos. Trans. R. Soc., 1995, A351, 595-610.

13. Williams, J. Fracture Mechanics in Solids. J. Wiley, New York, 1984.

14. Hasin, Z. Thermoelastic properties of fiber composites with imperfect interface. Mech. Mater., 1990, 8, 333-348.

15. Clyne, T. and Withers, P. An Introduction to Metal Matrix Composites. Cambridge Univ. Pr., 1993.

16. $\mathrm{Hu}, \mathrm{G}$. and Weng, G. Influence of thermal residual stresses on the composite macroscopic behavior. Mech. Mater., 1998, 27, 229-240.

17. Dunn, M. and Taya, M. Elastic-plastic thermal stresses and deformation of short fiber composites. J. Mater. Sci., 1994, 29, 2053-2062. 
18. Jiang, Z., Lian, J., Yang, D. and Dong, S. An analytical study of the influence of thermal residual stresses on the elastic and yield behaviour of short fibre reinforced composites. Mater. Sci. Eng., 1998, A248, 256-275.

19. Bruzzi, M., McHugh, P. and Linder, T. Micromechanical modelling of the static and cyclic loading of MMC. Int. J. Plast., 2001, 17, 565-599.

20. Liu, H. and Sun, L. Effect of thermal residual stresses on effective elastoplastic behaviour of MMC. Int. J. Solids Struct., 2004, 41, 2189-2203.

21. Hussainova, I. Some aspects of solid particle erosion of cermets. Tribology Int., 2001, 34, 8993.

22. Nairn, J. Exact and variational theorems for fracture mechanics of composites with residual stresses and imperfect interfaces. Int. J. Fract., 2000, 105, 243-271.

23. Nairn, J. Fracture mechanics of composites with residual thermal stresses. J.Appl. Mech., 1997, 64, 804-810.

24. Nairn, J. Fracture mechanics of composites with residual stresses and imperfect interfaces. Compos. Sci. Technol., 2001, 61, 2159-2167.

\section{Komposiitide erosioonkulumise mikromehaanika probleeme}

\section{Irina Hussainova}

On käsitletud komposiitide kulumist mikromehaanika seisukohalt eesmärgiga mõista paremini materjalide käitumist dünaamilistel koormustel ja prognoosida nende töövõimet. 